\title{
Effectiveness of Unified Protocols for Transdiagnostic Treatment in Emotion Regulation of Mothers and Anxiety of Children with Type I Diabetes
}

\author{
Sogand Ghasemzadeh ${ }^{1}$ and Zahra Naghsh ${ }^{1, *}$ \\ ${ }^{1}$ Assistant Professor, Faculty of Psychology and Education, University of Tehran, Tehran, Iran
}

* Corresponding author: Zahra Naghsh, Faculty of Psychology and Education, University of Tehran, Tehran, Iran. Email: z.naghsh@ut.ac.ir

Received 2020 September 17; Revised 2020 0ctober 15; Accepted 2020 0ctober 24

\begin{abstract}
Background: Type I diabetes (T1DT1D) is recognized as one of the most prevalent chronic diseases in children. It is accompanied by potentially life-threatening complications which affect the mood, personality, and emotions of children and their families.

Objectives: The present study aimed to assess the effectiveness of the unified protocols for transdiagnostic treatment program in emotion regulation of mothers and anxiety of children with T1D.

Methods: The present experimental study was conducted using the pretest-posttest follow-up control group design. The statistical population included all children with T1D within the age range of 9-11 years T1Dand their mothers who were referred to Iran Diabetes Association in Tehran in 2019-2020. The statistical sample was selected via the convenience (purposive) sampling method from among children with T1D and their mothers, and the subjects were randomly assigned to two experimental and control groups. The Cognitive Emotion Regulation Questionnaire (CERQ) developed by Garnefski et al. and Spence Children's Anxiety Scale (SCAS) were completed in the pretest, posttest, and follow-up. Diabetic children and their mothers received 15 sessions of the unified protocols for transdiagnostic treatment, while no special training was provided to the control group.

Results: The results of the present study indicated that the three measurements performed in pretest, posttest, and follow-up significantly differed regarding children's anxiety and mothers' emotion regulation strategies (e.g., catastrophizing, coping and acceptance, positive thinking, and blaming others) pointing to the effectiveness of transdiagnostic treatment $(\mathrm{P}=0.000)$.

Conclusion: The obtained results suggested the effectiveness of the unified protocols for transdiagnostic treatment program in reducing the anxiety of children with type 1 diabetes and improving the emotion regulation of their mothers.

Keywords: Anxiety, Diabetes, Emotion regulation, Transdiagnostic treatment
\end{abstract}

\section{Background}

Type I diabetes (T1D) is one of the most common endocrine diseases in childhood and adolescence and a major health problem in children across the globe (1). This chronic disease requires lifestyle changes to maintain and control blood glucose and avoid hypoglycemia. Moreover, it exerts a major impact on the psychological and psychosocial functioning of this age group and the resources of health systems (2). In 2015, the estimates from the International Diabetes Federation showed that approximately 86,000 children under the age of 15 are annually infected with this disease worldwide. Currently, in Iran, the rate of $\mathrm{T} 1 \mathrm{D}$ patients has been reported to be between $5 \%$ and $10 \%$ to which one percent is added annually (3). The diagnosis of diabetes in children presents daunting challenges to parents (4) affecting both the child and the psychological burden of the disease perceived by the parents $(5,6)$. Some symptoms, such as shock and grief, post-traumatic stress disorder, and increased levels of anxiety and depression, are common among parents of children diagnosed with T1D (7). In a systematic review study, Jones et al. (8) reported the prevalence of maternal psychological distress, followed by emotional dysregulation, to be between $20 \%-30 \%$. Numerous articles have indicated that emotional problems of mothers exert a negative impact on children's metabolic control (9-13). A previous study stated that daily insulin injections or fingertip blood sample collection to control blood glucose have different psychological effects on children and provoke anxiety, fear, and distress in children and families (14-17). One of the newest therapies for the treatment of psychological distress is trans-diagnostic treatment $(18,19)$ which reduces the symptoms of anxiety and depression in children's parents. Several studies confirmed the effectiveness of this treatment for patients with a range of mood disorders and heterogeneous emotional anxiety disorders in the post-treatment and follow-up stages (20-25). The modification of threatening factors and emotion regulation by the provision of appropriate information and training can lead to the empowerment of mothers and their more effective involvement in taking care of their diabetic children. In general, emotion regulation can influence the physical and mental performance of children and their mothers in experiencing emotions (15). Nevertheless, just a few studies have investigated the correlations between T1D and emotion regulation, and little is known about the impact of Usual 
Psychosocial Care (UPC) on mothers' emotion regulation and anxiety in children with T1D.

\section{Objectives}

The current study aimed to evaluate the effectiveness of the unified protocols for transdiagnostic treatment program in emotion regulation of mothers and reduced anxiety of children with T1D.

\section{Methods}

3.1. Study design, participants, as well as sample size and allocation

This experimental study was carried out on 16 children with diabetic type 1 ( within the age range of 9-11 years old) and their mothers who were referred to Tehran Diabetes and Treatment Centers from 21 February-19 April 2020 (Tehran, Iran). The required sample size was estimated at 8 patients in each group based on the t-test formula $(n 1=n 2)$ with an effect size of 2 and a dropout rate of $10 \%(\alpha=5 \%, \beta=10 \%)$.
Therefore, 16 diabetic patients were selected via convenience sampling and randomly assigned to two groups $(n=8)$ using block randomization methods.

\subsection{Inclusion and exclusion criteria}

The inclusion criteria were as follows: 1) the age range of 9-11 years, 2) diagnosis of T1D, 3) insulin injection at least once and at most three times a day, 4) being diabetic at least for 6 months after the diagnosis of diabetes, 5) non-use of psychiatric drugs at least for 1 month, 6) literacy, 7) lack of other diseases, 8) the ability to participate in regular training sessions, and 9) informed consent to participate in the research project. On the other hand, the exclusion criteria entailed: 1) absence for more than two sessions, 2) missing information in medical records, and 3) noncooperation of parents and children (Figure 1).

\subsection{Intervention}

The patients were randomly assigned to two groups of experiment and control. The experimental group received 15 unified transdiagnostic treatment

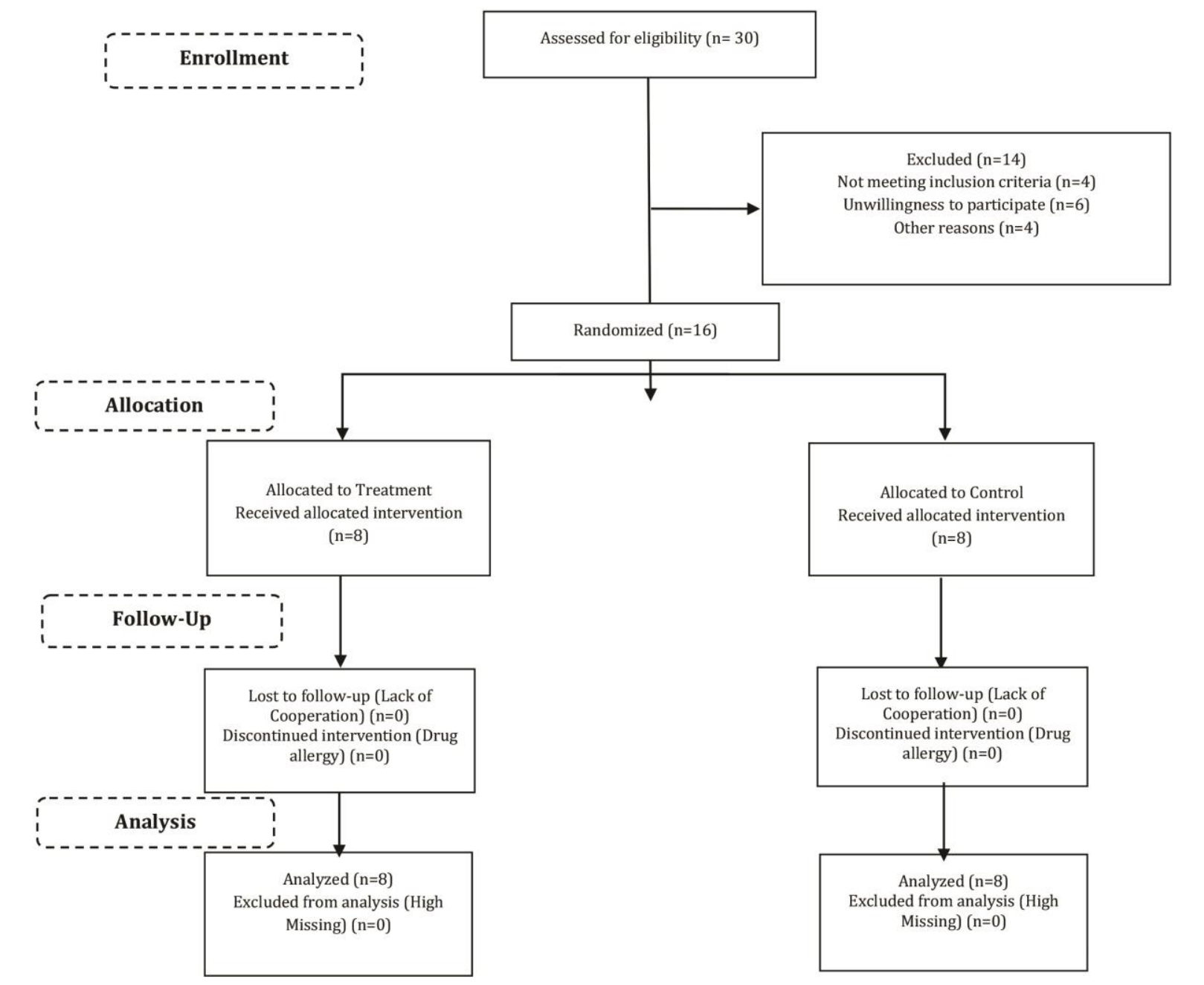

Figure 1. Study Follow up diagram 
sessions therapy in the form of 60-minute weekly sessions, while the control group received no treatment. After the end of the treatments, the two groups were post-tested. Finally, after a 3-month follow-up, both treatment and control groups were again asked to answer the relevant questionnaire.

The Transdiagnostic treatment protocol is a guide for therapists and clients to analyze the treatment process consisting of five therapeutic components which are designed to address the central aspects of emotion processing and regulation of emotional experiences. These five main therapeutic components are: 1) providing psychological training about emotions and raising awareness about them, 2) increasing cognitive flexibility, 3) identifying and preventing emotion avoidance models and emotioninduced maladaptive behaviors, 4) tolerating the physical sensations associated with the emotion and 5) situation-based and internal emotion-focused exposure. These components follow an introductory section focused on increasing motivation and readiness for change and involvement in the treatment process (20). This protocol was implemented for children in 15 60-minute sessions in parallel and simultaneously for parents in 16 60minute sessions (18):

A summary of therapy protocols is provided in Table1.

Table 1. Content of the training sessions for children and parents

\begin{tabular}{|c|c|c|}
\hline Session & Content of children's training sessions & Content of mothers' training sessions \\
\hline $\begin{array}{l}\text { First } \\
\text { session }\end{array}$ & $\begin{array}{l}\text { Introducing the structure of treatment to children, } \\
\text { identifying the most important problems, establishing } \\
\text { understanding and unity between group members and } \\
\text { the therapist, increasing their emotional awareness }\end{array}$ & $\begin{array}{l}\text { Introducing the five structures and skills to mothers, } \\
\text { introducing the three-part model of emotions to parents, } \\
\text { discussing the avoidance cycle and other emotional } \\
\text { behaviors }\end{array}$ \\
\hline $\begin{array}{l}\text { Second } \\
\text { session }\end{array}$ & $\begin{array}{l}\text { Teaching the identification and grading of different } \\
\text { emotions, normalizing emotional experiences, introducing } \\
\text { the three components of emotional experience, helping } \\
\text { children understand the avoidance cycle }\end{array}$ & $\begin{array}{l}\text { Becoming familiar with the four emotional parenting } \\
\text { behaviors and their opposite parenting behaviors, } \\
\text { discussing the provision of positive reinforcement as a } \\
\text { parenting behavior with criticism }\end{array}$ \\
\hline $\begin{array}{l}\text { Third } \\
\text { session }\end{array}$ & $\begin{array}{l}\text { Learning the concept of opposite action, using scientific } \\
\text { experiments for emotional behaviors and opposite } \\
\text { behavior, learning to track emotions and activities }\end{array}$ & $\begin{array}{l}\text { Becoming familiar with scientific experiments for the } \\
\text { behavior opposite to emotional behaviors, having a } \\
\text { discussion with mothers about how to support children in } \\
\text { scientific education focused on grief and sadness, providing } \\
\text { mothers with } 10 \text { ways to strengthen the child }\end{array}$ \\
\hline $\begin{array}{l}\text { Fourth } \\
\text { session }\end{array}$ & $\begin{array}{l}\text { Describing the concept of body clues and their } \\
\text { relationship with intense emotions, learning how to } \\
\text { identify body clues related to different emotions, teaching } \\
\text { the body scan skill to understand body clues }\end{array}$ & $\begin{array}{l}\text { Teaching the concept of somatization, training how to } \\
\text { perform a body scan, familiarizing parents with sensory } \\
\text { exposure and practicing sensory exposure in the session, } \\
\text { teaching how to empathize with children }\end{array}$ \\
\hline $\begin{array}{l}\text { Fifth } \\
\text { session }\end{array}$ & $\begin{array}{l}\text { Introducing the concept of flexible thinking, teaching how } \\
\text { to identify mental traps }\end{array}$ & $\begin{array}{l}\text { Becoming familiar with the concept of cognitive flexibility } \\
\text { and four common cognitive traps, discussing emotional } \\
\text { parenting behavior with a focus on instability and its } \\
\text { opposite parenting behavior, strengthening stable discipline }\end{array}$ \\
\hline $\begin{array}{l}\text { Sixth } \\
\text { session }\end{array}$ & $\begin{array}{l}\text { Introducing the concept of emotions detective in a non- } \\
\text { emotional way using a coding game, using the detective } \\
\text { thinking skill }\end{array}$ & $\begin{array}{l}\text { Introducing the concept of cognitive detective, practicing } \\
\text { detective thinking, familiarizing mothers with maximum } \\
\text { emotional parenting behavior/ maximum support and } \\
\text { opposite parenting behavior, giving healthy independence }\end{array}$ \\
\hline $\begin{array}{l}\text { Seventh } \\
\text { session }\end{array}$ & $\begin{array}{l}\text { Introducing problem-solving using a non-emotional } \\
\text { example or problem-solving game, practicing problem- } \\
\text { solving using more personal and more specific scenarios }\end{array}$ & $\begin{array}{l}\text { Introducing problem-solving steps, discussing the } \\
\text { application of problem-solving for interpersonal conflicts, } \\
\text { examining mothers' efforts for giving healthy independence }\end{array}$ \\
\hline $\begin{array}{l}\text { Eighth } \\
\text { session }\end{array}$ & $\begin{array}{l}\text { Learning the skill of "experiencing my emotions", teaching } \\
\text { to the children by contact with the present moment } \\
\text { playing the game of "using my five senses", introducing } \\
\text { the idea of non-judgmental awareness }\end{array}$ & $\begin{array}{l}\text { Discussing the importance of learning to experience } \\
\text { emotions, becoming familiar with the concept of contact } \\
\text { with the present moment, and non-judgmental awareness }\end{array}$ \\
\hline $\begin{array}{l}\text { Ninth } \\
\text { session }\end{array}$ & $\begin{array}{l}\text { Reviewing the emotion detective skill, reviewing the } \\
\text { concepts of emotional behaviors and opposite action to } \\
\text { prepare people for a new type of scientific experiment } \\
\text { called exposure, performing exposure using a doll or } \\
\text { other objects }\end{array}$ & $\begin{array}{l}\text { Becoming familiar with the concept of situational emotion } \\
\text { exposures as another type of scientific experiment, } \\
\text { explaining the role of mothers in performing the exposure at } \\
\text { home, becoming familiar with emotional parenting behavior } \\
\text { and extreme modeling of intense emotions and avoiding its } \\
\text { opposite parenting behavior, healthy emotional modeling }\end{array}$ \\
\hline $\begin{array}{l}\text { Tenth } \\
\text { session }\end{array}$ & $\begin{array}{c}\text { Reviewing the concept of using scientific experiments to } \\
\text { deal with intense emotions, introducing the idea of safety } \\
\text { behaviors and subtle avoidance behaviors (such as } \\
\text { distraction), practicing a scientific experiment to deal } \\
\text { with intense emotions }\end{array}$ & $\begin{array}{l}\text { Reviewing the concept of exposure to emotion and } \\
\text { discussing the application of exposure for different } \\
\text { symptoms }\end{array}$ \\
\hline $\begin{array}{l}\text { Eleventh to } \\
\text { fourteenth } \\
\text { sessions }\end{array}$ & $\begin{array}{l}\text { Planning and implementing situational exposure to } \\
\text { emotion, planning and implementing exposure activities }\end{array}$ & $\begin{array}{l}\text { Planning and implementing situational exposure to } \\
\text { emotion, planning and implementing exposure activities }\end{array}$ \\
\hline $\begin{array}{l}\text { Fifteenth } \\
\text { session }\end{array}$ & $\begin{array}{l}\text { Reviewing the emotions detective skills learned in the } \\
\text { UPC program, planning to deal with intense emotions in } \\
\text { the future, appreciating the progress }\end{array}$ & $\begin{array}{l}\text { Reviewing the emotions detective skills and opposite } \\
\text { parenting behaviors, discussing and appreciating each child's } \\
\text { progress, planning to maintain and enhance post-treatment } \\
\text { progress, distinguishing between regression and relapse, and } \\
\text { helping parents identify the warning signs of relapse }\end{array}$ \\
\hline
\end{tabular}




\subsection{Research Tools}

The Cognitive Emotion Regulation Questionnaire developed by Garnefski et al. and Spence Children's Anxiety Scale were employed in the current study.

The Cognitive Emotion Regulation Questionnaire (CERQ) was developed by Garnefski, Kraaij, and Spinhoven (26). This multidimensional questionnaire is a self-report tool consisting of 36 items rated on a five-point Likert scale ranging from always to never. The Persian version of this questionnaire was validated by Samani and Jokar (27). In this questionnaire, the respondents are asked to determine their reactions in the face of recently experienced threatening experiences and stressful life events by answering five questions that evaluate a strategy for emotion regulation. The main version of this questionnaire includes 9 subscales and 36 items. In this questionnaire, self-blame, blaming others, rumination, and catastrophizing indicate negative emotion regulation strategies, while acceptance, refocus on planning, positive refocusing, positive reappraisal, and putting into perspective signify positive emotion regulation strategies. The items in this questionnaire are rated on a five-point Likert scale (always, often, usually, sometimes, never). As reported by the designers of this questionnaire, the reliability of this questionnaire was confirmed rendering Cronbach's alpha coefficients of $0.91,0.87$, and 0.93 for positive strategies, negative strategies, and the whole questionnaire, respectively. In the current study, a 26-item questionnaire with four subscales was applied and Cronbach's alpha coefficients were obtained at $0.82,0.79,0.80,0.74$, 0.80 , for self-blame and catastrophizing, coping and acceptance, positive thinking, blaming others, and the whole questionnaire, respectively.

Spence Children's Anxiety Scale (SCAS) developed by Spence et al. comprises 45 questions (28) and aims to measure and evaluate the anxiety of children aged 8-15 years based on the classification of the Diagnostic and Statistical Manual of Mental Disorders. This questionnaire which was translated into Persian by Mousavi, Moradi, Farzad, Mahdavi, and Spence(29) is available in two versions for children and parents, and both versions consist of six scales (separation anxiety, social anxiety, obsessivecompulsive disorder, market panic, generalized anxiety, and fear of bodily harm). The items are rated on a five-point scale (very low, low, partly, high, and very high). This questionnaire has high validity, its internal consistency coefficient (alpha coefficient) was calculated at 0.92 , its reliability was obtained at 0.75 using the test-retest method (one-week interval), and the correlation of its items was reported as 0.30-0.76. Five types of content validity, concurrent validity, construct validity, diagnostic validity, and factor validity were assessed for this test, all of which confirmed the high efficiency of this tool in measuring the severity of anxiety.

\subsection{Ethical considerations}

All the participants in this research program were aware of the used methodology after a comprehensive explanation. The written informed consent was obtained from all participants after presenting enough explanations about the study objectives. The research procedure was in accordance with the Human Ethics Committee of the Tehran University of Medical Sciences (IR.UT.PSYEDU.REC.1399.024).

\subsection{Statistical analysis}

The data were analyzed in SPSS software (version 24) using descriptive statistical methods (frequency, percentage, mean, and standard deviation), Levene's test, Kolmogorov-Smirnov test, t-test. Moreover, the repeated-measures analysis of variance (ANOVA) was used to calculate within and between-group variability. The significance level in the present study was equal to 0.05 .

\section{Results}

In terms of demographic variables, the mean age scores of the subjects were reported as $10.8 \pm 3.98$ and $10.10 \pm 3.87$ in the control and experimental groups, respectively. The baseline variables between the two groups are presented in Table 2 . The result demonstrated that the two groups were the same according to the baseline variable.

Table 3 displays the descriptive information about anxiety and emotion regulation components in three stages of pretest, posttest, and follow-up in the experimental and control groups.

Repeated-measures ANOVA was used to evaluate the effect of the integrated transdiagnostic treatment program on anxiety and emotion regulation. The assumptions of repeated measures analysis of variance, including normality, were examined by the Kolmogorov-Smirnov test. The results of this test

Table 2. Baseline variables between the two groups

\begin{tabular}{|c|c|c|c|c|c|}
\hline \multirow{3}{*}{ Variables } & \multicolumn{4}{|c|}{ Group } & \multirow{3}{*}{ P-value } \\
\hline & \multicolumn{2}{|c|}{ Treatment } & \multicolumn{2}{|c|}{ Control } & \\
\hline & Mean & Standard Deviation & Mean & Standard Deviation & \\
\hline Anxiety & 3.80 & 0.56 & 3.74 & 0.53 & 0.759 \\
\hline Catastrophizing & 3.73 & 0.58 & 3.66 & 0.52 & 0.732 \\
\hline Acceptance & 3.15 & 0.68 & 3.13 & 0.68 & 0.941 \\
\hline Positive thinking & 3.14 & 0.68 & 3.11 & 0.67 & 0.902 \\
\hline Blaming others & 3.70 & 0.57 & 3.67 & 0.52 & 0.878 \\
\hline
\end{tabular}




\begin{tabular}{|c|c|c|c|c|c|c|}
\hline \multirow{3}{*}{ Variables } & \multirow{3}{*}{ Time } & \multicolumn{4}{|c|}{ Group } & \multirow{3}{*}{ P-value } \\
\hline & & \multicolumn{2}{|r|}{ Treatment } & \multicolumn{2}{|r|}{ Control } & \\
\hline & & Mean & Standard Deviation & Mean & Standard Deviation & \\
\hline \multirow{4}{*}{ Anxiety } & Pre & 3.80 & 0.56 & 3.74 & 0.53 & 0.759 \\
\hline & Post & 3.18 & 0.55 & 3.70 & 0.54 & 0.010 \\
\hline & Follow (3 Month Later) & 3.09 & 0.51 & 3.79 & 0.56 & 0.001 \\
\hline & P-value & \multicolumn{2}{|r|}{0.001} & & 0.223 & 0.04 \\
\hline \multirow{4}{*}{ Catastrophizing } & Pre & 3.73 & 0.58 & 3.66 & 0.52 & 0.732 \\
\hline & Post & 3.08 & 0.55 & 3.60 & 0.54 & 0.009 \\
\hline & Follow (3 Month Later) & 2.99 & 0.58 & 3.71 & 0.55 & 0.001 \\
\hline & P-value & \multicolumn{2}{|r|}{$<0.001$} & \multicolumn{2}{|r|}{0.197} & 0.041 \\
\hline \multirow{4}{*}{ Acceptance } & Pre & 3.15 & 0.68 & 3.13 & 0.68 & 0.941 \\
\hline & Post & 3.82 & 0.55 & 3.14 & 0.67 & 0.003 \\
\hline & Follow ( 3 Month Later) & 3.82 & 0.56 & 3.10 & 0.67 & 0.002 \\
\hline & P-value & \multicolumn{2}{|r|}{0.001} & \multicolumn{2}{|r|}{0.368} & 0.037 \\
\hline \multirow{4}{*}{$\begin{array}{l}\text { Positive } \\
\text { thinking }\end{array}$} & Pre & 3.14 & 0.68 & 3.11 & 0.67 & 0.902 \\
\hline & Post & 3.82 & 0.53 & 3.12 & 0.67 & 0.002 \\
\hline & Follow ( 3 Month Later) & 3.82 & 0.55 & 3.10 & 0.66 & 0.002 \\
\hline & P-value & \multicolumn{2}{|r|}{$0.002^{0.53}$} & \multicolumn{2}{|r|}{0.968} & 0.032 \\
\hline \multirow{4}{*}{ Blame others } & Pre & 3.70 & 0.57 & 3.67 & 0.52 & 0.878 \\
\hline & Post & 3.07 & 0.56 & 3.60 & 0.53 & 0.007 \\
\hline & Follow (3 Month Later) & 3.01 & 0.56 & 3.71 & 0.56 & 0.001 \\
\hline & P-value & \multicolumn{2}{|r|}{$0.001^{0.50}$} & \multicolumn{2}{|r|}{0.093} & 0.033 \\
\hline
\end{tabular}

demonstrated that the scores of anxiety and emotion regulation components were higher than 0.05 $(\mathrm{P}>0.05)$ in the experimental and control groups, pointing to the normality of data. Homogeneity of variances was also assessed using Levene's test. The results obtained from Levene's test for the variable of anxiety and emotion regulation components indicated the homogeneity of variances $(P>0.05)$. Moreover, the results of Box's $M$ test were not significant: Box's $M=22.65$ for the variable of anxiety and Box's $\mathrm{M}=13.79$ for the component of catastrophizing, Box's $\mathrm{M}=25.90$ for coping and acceptance, Box's $M=19.71$ for positive thinking, and Box's M=17.67 for blaming others $(\mathrm{P}>0.05)$. Therefore, the assumption of the equality of covariance matrices was confirmed. The sphericity assumption was assessed based on Mauchly's test and was confirmed in all variables. The results of this research disclosed that the variables of anxiety, catastrophizing, coping and acceptance, positive thinking, and blaming others were consistent at the commencement of the study in the two groups. Nonetheless, at the end of the study and follow-up, the changes were significant only in the intervention group, and the control group did not show any significant changes. This in turn indicated the significant effect of the intervention group, compared to the control group (Figure 2).

\section{Discussion}

The findings of the present study pointed to a significant increase in mothers' emotion regulation and a significant decrease in anxiety among children with T1D. This finding is in agreement with the results of previous studies (19-25,30,31). In fact, mothers' anxiety and stress are passed on to their children since they are considered the most important person in children's support system (22).

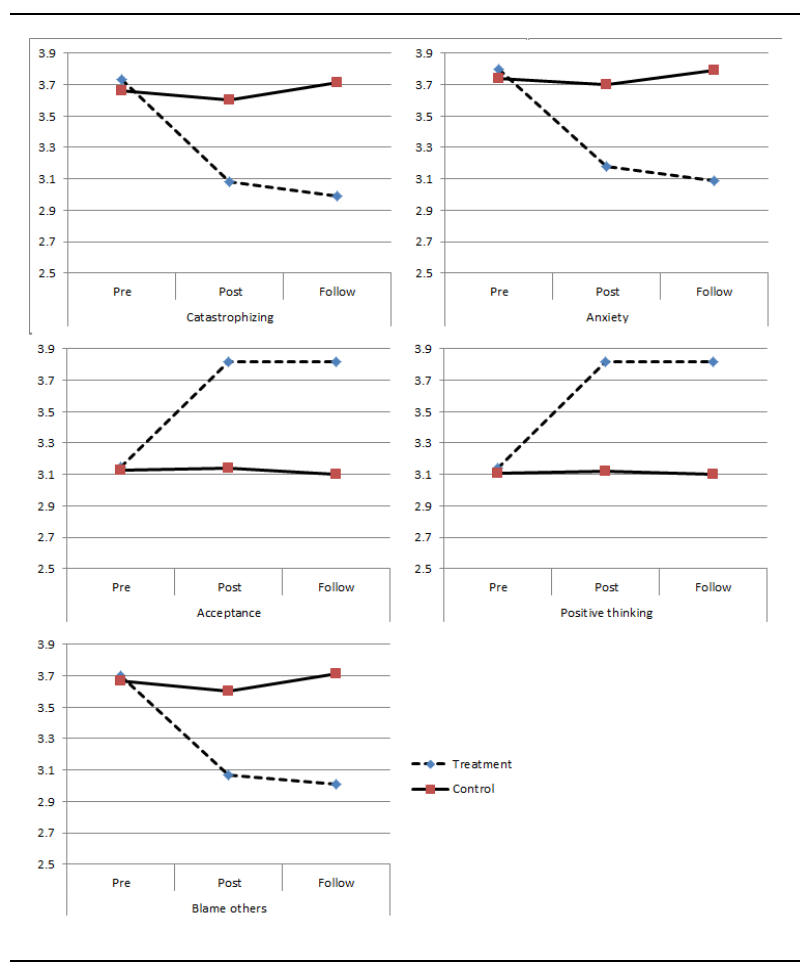

Figure 2. Study Follow up diagram

UPC provides people with positive cognitive emotion regulation strategies and helps them to deal with their problems by reducing negative emotions and improving cognitive and emotional functioning (19). Therefore, UPC can be regarded as an important factor in improving emotion regulation and reducing the psychological problems of mothers of children with T1D.

Moreover, it seems that the application of UPC in the context of stress and illness can help people to use efficient strategies by reducing negative emotions and enhancing positive emotions (20). 
Furthermore, it can be stated that UPC, with targeted control of the stressor, decreases or eliminates the pressure arising therefrom. Obviously, the preferred treatment for diabetes is a multifaceted treatment, one of the main aspects of which is working on the ability to cope with stress and reduce anxiety, depression, and other psychiatric disorders, which in turn, affect the performance of individuals in other aspects of treatment (23). UPC emphasizes the adaptive and functional nature of emotions and primarily seeks to identify and modify maladaptive efforts to regulate experiences, thereby facilitating proportionate processing and silencing disproportionate emotional responses to internal and external cues (30). Given that people with T1D struggle with a negative and stressful experience in their lives, the adoption of these strategies can exert positive effects on the reduction of anxiety (13). New theories in the field of emotion place emphasis on the positive and adaptive role of emotion. The related studies have shown that individuals' ability for cognitive emotion regulation can play a crucial role in their adjustment to stressful life events (22). There is a clear connection between experience of negative events, emotion regulation strategies, and problems such as anxiety. Chronic anxiety in diabetic children puts them at the risk of isolation from peer groups and rejection (31). UPC provides individuals with positive cognitive emotion regulation strategies and helps them to deal with their problems by reducing negative emotions and improving cognitive and emotional functioning (24). Therefore, the integrated transdiagnostic treatment program can be regarded as an important factor in reducing the psychological problems of children with T1D. It also seems that the application of UPC in the context of stress and illness can facilitate the use of efficient strategies by decreasing negative emotions and enhancing positive emotions (23).

The notable limitations of the present study include the small sample size, non-participation of fathers in the UPC intervention program, and the restriction of participants to the patients of the Diabetes Association. It is recommended that in future studies, larger samples be considered for the generalization and effectiveness of the UPC program, along with the participation of both parents.

\section{Conclusion}

The obtained results indicated the effectiveness of unified protocols for transdiagnostic treatment program in the enhancement of mothers' emotion regulation and the reduction of anxiety among children with T1D.

\section{References}

1. American Diabetes Association Standards of medical care in diabetes-2017 abridged for primary care providers. Clin Diabetes. 2017;35:5-26. doi: 10.2337/cd16-0067. [ PubMed: 28144042].

2. Butwicka A, Fendler W, Zalepa A, Szadkowska A, ZawodniakSzalapska M, Gmitrowicz A, et al. Psychiatric disorders and health-related quality of life in children with type 1 diabetes mellitus. Psychosomatics. 2016;57(2):185-93. doi: 10.1016/j. psym.2015.11.001. [PubMed: 26774893].

3. Ellison JK, Kouros CD, Papp LM, Cummings EM. Interplay between marital attributions and conflict behavior in predicting depressive symptoms. J Fam Psychol. 2016; 30(2):286-95. doi: 10.1037/fam0000181. [PubMed: 26751758].

4. Hou Y, Jiang F, Wang X. Marital commitment, communication and marital satisfaction: An analysis based on actor-partner interdependence model. Int J Psychol.. 2019;54(3):369-76. doi: 10.1002/ijop.12473. [PubMed: 29318606].

5. Aggarwal S, Kataria D, Prasad S. A comparative study of quality of life and marital satisfaction in patients with depression and their spouses. Asian J Psychiatr. 2017;30:65-70. doi: 10.1016/j.ajp.2017.08.003. [PubMed: 28802799].

6. Bloch L, Haase CM, Levenson RW. Emotion regulation predicts marital satisfaction: more than a wives' tale. Emotion. 2014; 14(1):130-44. doi: 10.1037/a0034272. [PubMed: 24188061].

7. Golfenshtein N, Srulovici E, Medoff-Cooper B. Investigating parenting stress across pediatric health conditions - a systematic review. Issues Compr Pediatr Nursi. 2015:1-49. doi: 10.3109/01460862.2015.1078423. [PubMed: 26367769].

8. Jones A, Olsen MZ, Perrild HJ, Willaing I. The psychological impact of living with diabetes: Descriptive findings from the DAWN2 study in Denmark. Prim Care Diabetes. 2016;10(1):836. doi: 10.1016/j.pcd.2015.03.008. [PubMed: 25890864].

9. Curtis K, Foster K, Mitchell R, Van C. Models of care delivery for families of critically Ill children: an integrative review of international literature. J Pediatr Nurs. 2016;31(3):330-41. doi: 10.1016/j.pedn.2015.11.009. [PubMed: 26699441].

10. Nieuwesteeg AM, Hartman EE, Aanstoot HJ, van Bakel HJ, Emons WH, van Mil E, et al. The relationship between parenting stress and parent-child interaction with health outcomes in the youngest patients with type 1 diabetes (0-7 years). Eur J Pediatr. 2016;175(3):329-38. doi: 10.1007/s00431-015-2631-4. [PubMed: 26438336].

11. Özgüç S, Tanriverdi D. Relations between depression level and conflict resolution styles, marital adjustments of patients with major depression and their spouses. Arch Psychiatr Nurs. 2018;32(3):337-42. Epub 2018/05/23. doi: 10.1016/j.apnu.2017.11.022. [PubMed: 29784211].

12. Duong MT, Kelly BM, Haaland WL, Matsumiya B, Huey SJ, McCarty CA.. Mediators and moderators of a school-based cognitive-behavioral depression prevention program. Cognit Ther Res. 2016;40(5):705-16. doi: 10.1007/s10608-016-97802. [PubMed: 27795599].

13. Polanczyk GV, Salum GA, Sugaya LS, Caye A, Rohde LA. Annual research review: A meta-analysis of the worldwide prevalence of mental disorders in children and adolescents. J Child Psychol Psychiatry. 2015;56(3):345-65. doi: 10.1111/jcpp.12381. [PubMed: 25649325].

14. Sloan E, Hall K, Moulding R, Bryce S, Mildred H, Staiger PK. Emotion regulation as a transdiagnostic treatment construct across anxiety, depression, substance, eating and borderline personality disorders: A systematic review. Clin Psychol Rev. 2017;57:141-63. doi: 10.1016/j.cpr.2017.09.002. [PubMed: 28941927].

15. Kiecolt-Glaser JK, Jaremka L, Andridge R, Peng J, Habash D, Fagundes CP, et al. Marital discord, past depression, and metabolic responses to high-fat meals: Interpersonal pathways to obesity. Psychoneuroendocrinology. 2015;52:239-50. doi: 10.1016/j.psyneuen.2014.11.018. [PubMed: 25506778].

16. Bentley $\mathrm{KH}$. Applying the unified protocol transdiagnostic treatment to nonsuicidal self-injury and co-occurring emotional disorders: A case illustration. J clin psychol. 2017; 73(5):547-58. doi: 10.1002/jclp.22452. [PubMed: 28221666].

17. Laposa JM, Mancuso E, Abraham G, Loli-Dano L. Unified protocol transdiagnostic treatment in group format. Behav Modif. 2017;41(2):253-68. doi: 10.1177/0145445516667664. 
[PubMed: 27591430].

18. Barlow DH, Farchione TJ, Bullis JR, Gallagher MW, Murray-Latin $\mathrm{H}$, Sauer-Zavala S, et al. The unified protocol for transdiagnostic treatment of emotional disorders compared with diagnosisspecific protocols for anxiety disorders: A randomized clinical trial. JAMA psychiatry. 2017;74(9):875-84. doi: 10.1001/jamapsychiatry.2017.2164. [PubMed: 28768327].

19. Talkovsky AM, Green KL, Osegueda A, Norton PJ. Secondary depression in transdiagnostic group cognitive behavioral therapy among individuals diagnosed with anxiety disorders. J Anxiety Disord. 2017;46:56-64. doi: 10.1016/j.janxdis. 2016.09.008. [PubMed: 27707524]

20. Bullis JR, Fortune MR, Farchione TJ, Barlow DH. A preliminary investigation of the long-term outcome of the unified protocol for transdiagnostic treatment of emotional disorders. Compr Psychiatry. 2014;55(8):1920-7. doi: 10.1016/j.comppsych. 2014.07.016. [PubMed: 25113056].

21. Ito M, Horikoshi M, Kato N, Oe Y, Fujisato H, Nakajima S, et al. Transdiagnostic and transcultural: pilot study of unified protocol for depressive and anxiety disorders in japan. Behav Ther. 2016;47(3):416-30. doi: 10.1016/j.beth.2016.02.005. [PubMed: 27157034].

22. Kennedy SM, Bilek EL, Ehrenreich-May J. A randomized controlled pilot trial of the unified protocol for transdiagnostic treatment of emotional disorders in children. Behav Modif. 2019;43(3):330-60. doi: 10.1177/0145445517753940. [PubMed: 29374963].

23. Chu BC, Crocco ST, Esseling P, Areizaga MJ, Lindner AM, Skriner LC. Transdiagnostic group behavioral activation and exposure therapy for youth anxiety and depression: Initial randomized controlled trial. Behav Res Ther. 2016;76:65-75. doi: 10.1016/j.brat.2015.11.005. [PubMed: 26655958].

24. Blake MJ, Trinder JA, Allen NB. Mechanisms underlying the association between insomnia, anxiety, and depression in adolescence: Implications for behavioral sleep interventions. Clin Psychol Rev. 2018;63:25-40. doi: 10.1016/j.cpr.2018.05.006. [PubMed: 29879564].

25. García-Escalera J, Valiente RM, Chorot P, Ehrenreich-May J, Kennedy SM, Sandín B. The spanish version of the unified protocol for transdiagnostic treatment of emotional disorders in adolescents (up-a) adapted as a school-based anxiety and depression prevention program: study protocol for a cluster randomized controlled trial. JMIR Res Protoc. 2017;6(8):e149. doi: 10.2196/resprot.7934. [PubMed: 28827212].

26. Garnefski N, Kraaij V, Spinhoven P. Negative life events, cognitive emotion regulation and emotional problems. Pers Individ Dif. 2001;30(8):1311-27.

27. Samani S, Jokar B. Check the credentials and reliability is a short form of psychological pressure and anxiety depression scale. J Soc Sci Hum Univ Shiraz. 2007;26(3):65-77. doi: 10.1007/s11948-017-9989-9. [PubMed: 29127671].

28. Spence SH, Barrett PM, Turner CM. Psychometric properties of the spence children's anxiety scale with young adolescents. J Anxiety Disord. 2003;17(6):605-25. doi: 10.1016/s08876185(02)00236-0. [PubMed: 14624814].

29. Mousavi R, Moradi AR, Farzad V, Mahdavi S. Psychometric properties of the spence children's anxiety scale with an Iranian sample. Int J Psychol. 2007;1(1):17-26.

30. Jakubovski E, Bloch MH. Anxiety disorder-specific predictors of treatment outcome in the coordinated anxiety learning and management (CALM) trial. Psychiatr Q. 2016;87(3):445-64. doi: 10.1007/s11126-015-9399-6. [PubMed: 26563229].

31. Fernández-Martínez I, Morales A, Espada JP, Essau CA, Orgilés M. Effectiveness of the program Super Skills For Life in reducing symptoms of anxiety and depression in young Spanish children. Psicothema. 2019;31(3):298-304. doi: 10.7334/psicothema2018.336. [PubMed: 31292045]. 